\title{
IMPROVED SUPERALLOY GRINDING PERFORMANCE WITH NOVEL CBN CRYSTALS
}

\author{
Sridhar Kompella and Kai Zhang \\ Diamond Innovations, Inc. \\ 6325 Huntley Road, Columbus OH 43229 USA
}

Keywords: Grinding, Superalloy, Inconel, CBN, Vitrified, Burn, Thermal damage

\begin{abstract}
The superior thermal properties of nickel-based superalloys that make them suitable for use in gas turbine blades and vanes also make them difficult to grind. Cubic boron nitride (CBN) crystals, which possess high thermal conductivity, lend themselves to superalloy grinding by dissipating the grinding heat more effectively than conventional abrasives. Even so, productivity is constrained by the propensity of superalloys to suffer thermal damage when using accelerated grinding parameters. Furthermore, the process economics hinge on maximizing grinding wheel re-profiling intervals and the overall wheel life. In this paper the performance of two novel CBN crystals in grinding Inconel 718 as function of the wheel life, the workpiece surface characteristics, and the process energy requirements is examined. The significantly improved performance of these new CBN crystals is compared with that from commercially available CBN. Possible mechanisms to explain the performance of the new crystals are discussed.
\end{abstract}

\section{Introduction}

The efficiency of aircraft and land-based gas turbine engines improves with increasing operating temperatures [1,2]. Nickel-based superalloys such as those in the Rene and Inconel families are routinely used in hot-stage turbine components such as blades, vanes, and nozzles. Superalloy materials have low thermal expansion coefficient and thermal conductivity and can retain their mechanical properties at temperatures in excess of $1000^{\circ} \mathrm{C}$. The turbine components are fabricated using investment casting techniques to achieve near net shape and to minimize postcasting processing. Even so, there is a need to finish grind these components to their final form and dimensional tolerance before the engine is assembled.

The functionally desirable thermal properties of superalloys also present significant challenges in grinding. For instance, the low thermal conductivity $\left(11.4 \mathrm{~W} / \mathrm{m} / \mathrm{K}\right.$ at $\left.20^{\circ} \mathrm{C}\right)$ of Inconel 718 [3] implies that its ability to dissipate grinding energy is limited. Higher wheel wear and the risk of superalloy undergoing local phase transformation (also known as grinding burn) necessarily inhibits [4] grinding productivity. The high material cost of superalloys also renders scrap generation prohibitively expensive.

Superalloy grinding has been traditionally conducted by aluminum oxide abrasives using a continuous-dress, creep-feed (CDCF) grinding process. The continuous dressing of the wheel is required to re-profile the rapidly wearing conventional wheel. While this also keeps the wheel sharp and avoids damaging the component, such non-productive dressing expends a significant amount of the abrasive and necessitates frequent wheel changeovers with the associated downtime. 
A more efficient way to grind superalloys involves the use of cubic boron nitride (CBN) wheels. $\mathrm{CBN}$ is the second-hardest material [5] after diamond. CBN can be synthesized to produce a variety of crystal shapes, colors, morphologies and physical properties which, in turn, can tailor grinding performance. Superalloy grinding is routinely done with single-layer CBN wheels or with vitrified bonded $\mathrm{CBN}$ wheels. The former cannot be re-conditioned and are discarded when the $\mathrm{CBN}$ layer wears away; the latter, on the other hand, facilitate periodic dressing. While vitrified $\mathrm{CBN}$ wheels require much less frequent dressing, their ability to grind with lower power opens the possibility of achieving higher removal rates and part throughput.

This paper is focused on vitrified $\mathrm{CBN}$ wheels alone and examines the grinding characteristics of Inconel 718 with three different kinds of CBN crystals. Further, the ability to accelerate the grinding process without damaging the workpiece is explored. An objective of the testing is to determine the extent to which the grinding process can be accelerated, without inducing thermal damage or incurring catastrophic wheel wear.
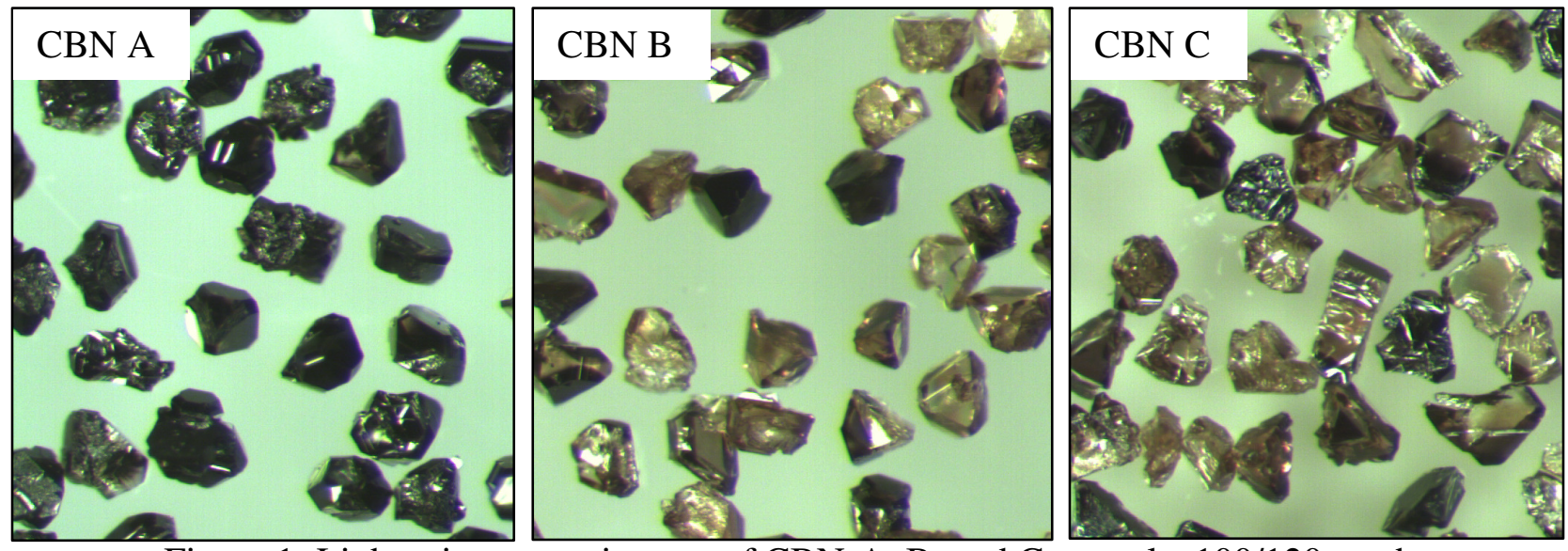

Figure 1: Light microscope images of CBN-A, B, and C crystals; 100/120 mesh.

\section{CBN Crystal Attributes}

Three distinct CBN crystal types of 100/120 mesh (nominally $151 \mu \mathrm{m}$ in diameter) were chosen for grinding tests. CBN A is a standard, commercially available CBN crystal that is widely used in a range of applications and was chosen as a benchmark in these tests. $\mathrm{CBN} B$ and $\mathrm{CBN} \mathrm{C}$ are newly synthesized experimental crystals.

Visually, CBN A is a black, blocky crystal with roughly textured facets (Figure 1). CBN B and CBN C are both light-brown in color; CBN B has smooth crystal facets while CBN $\mathrm{C}$ has a marginally rougher surface. Both $\mathrm{CBN} B$ and $\mathrm{CBN} C$ have sharp edges

CBN crystals are generally characterized [6] as a function of their friability using a metric known as Toughness Index (TI). In the TI test, a pre-determined quantity of CBN in a specific mesh size is enclosed in a vial with a tungsten carbide or steel ball and vibrated at a given frequency for a fixed time. The fraction of the CBN crystals that resist fracture down to a smaller sieve size is reported as TI; higher TI values indicate low friability. Figure 2 shows the TI of the three CBN crystals normalized with respect to $\mathrm{CBN} A$. On this scale, relative to $\mathrm{CBN} A, \mathrm{CBN} \mathrm{B}$ and $\mathrm{C}$ are significantly tougher crystals. In addition, the Thermal Toughness Index (TTI) test measures the thermal stability of these crystals which are subjected to the same TI test after being heated to $1000^{\circ} \mathrm{C}$ in an inert atmosphere for 15 minutes and subsequently cooled down. The TTI is a measure of the ability of the crystals to withstand in-process grinding temperature and elevated 
fabrication temperatures used with vitrified bonded wheels. Relative to CBN A, CBN B and C are significantly more thermally stable.

While the TI, TTI, and shape attributes are quantifiable indicators of CBN properties their ability to predict grinding performance is limited. The orientation of the crystals, their packing in the wheel and the ability to expose new cutting edges following abrasive contact with the workpiece is the key determinant of grinding performance.

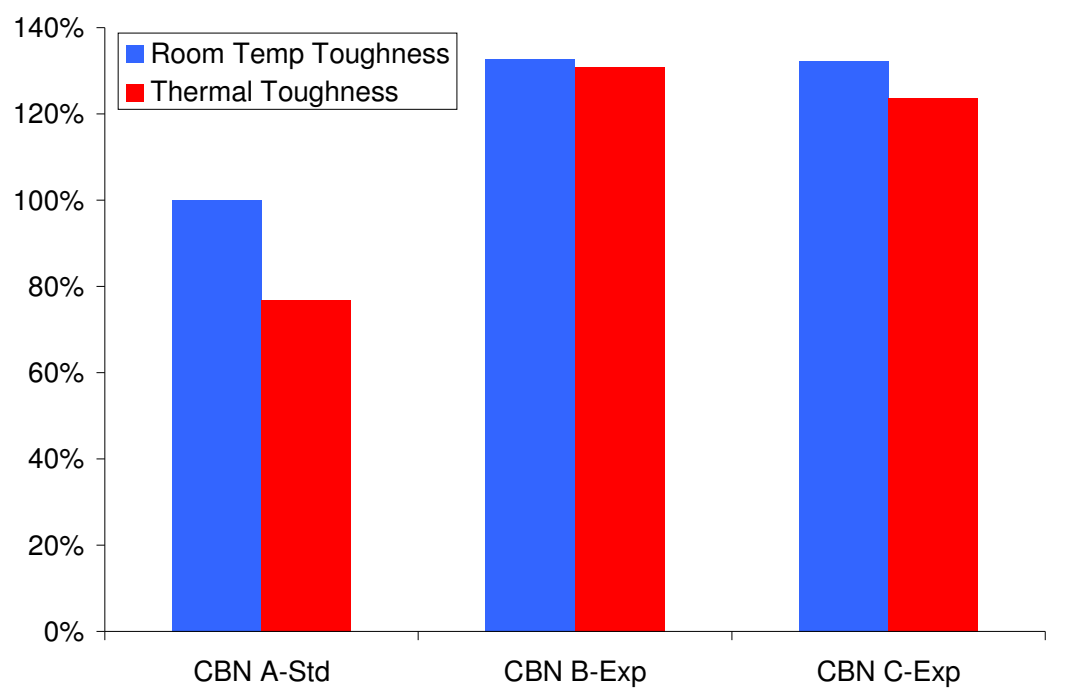

Figure 2: Relative friability of the $\mathrm{CBN}$ crystals

Grinding wheel and workpiece

\section{Experimental}

Vitrified bond wheels, $178 \mathrm{~mm}$ (diameter) $\times 6.35 \mathrm{~mm}$ (width), containing the three abrasive types (A, B, and C) of mesh size 100/120 (FEPA B151) were fabricated at 125 concentration. A concentration of 125 corresponds to $\mathrm{CBN}$ occupying $31.25 \%$ of the abrasive layer volume. The vitrified bond was characterized as possessing medium hardness and designed for identical levels of porosity in all the wheels. Duplicate wheels with each CBN type were tested to assess wheel manufacturing variability. For a given CBN, an acceptable wheel-to-wheel performance variability of $10 \%$ or less was recorded. For clarity in presentation, data from only one wheel per abrasive is shown in this document.

The specification of the vitrified $\mathrm{CBN}$ wheels and the truing conditions are shown in Table 1. All vitrified CBN wheels were identically conditioned using a metal bond diamond rotary truing disk. The velocity vectors for both the wheel and the truing disk were in the same direction. The speed ratio of truing disk and grinding wheel was maintained at 0.4. In addition, a truing lead $\left(\mathrm{s}_{\mathrm{d}}\right)$ of $254 \mu \mathrm{m} / \mathrm{rev}$ was chosen.

The nominal composition of the Inconel 718 (AMS 5772M) bars is shown in Table 2. The workpiece was resolution treated to $1750^{\circ} \mathrm{F}$ for one hour followed by a water quench. Precipitation heat treatment was carried out at $1325^{\circ} \mathrm{F}$ for 8 hours, followed by a furnace cool to $1150^{\circ} \mathrm{F}$ at which it was held for 8 hours followed by air cooling. The grain size was estimated to be ASTM number 10 (per ASTM-E-112-96) by the supplier. The microstructure of the asreceived workpiece is shown in Figure 3 after being treated with Tucks' Etch $\left(\mathrm{HCl} 45 \mathrm{ml}, \mathrm{HNO}_{3}\right.$ 
$15 \mathrm{ml}$, HF $15 \mathrm{ml}, \mathrm{H}_{2} \mathrm{O} 25 \mathrm{ml}$ ) for 25 seconds. The average Rockwell C hardness of Inconel 718 was measured to be 35 .

Creep-feed grinding conditions were employed on a 15-hp Blohm Precimat surface grinder. A depth of cut of $1.27 \mathrm{~mm}$, corresponding to a wheel-workpiece contact length of about $15 \mathrm{~mm}$, was used for all the tests. The product of the workpiece traverse rate and the depth of cut gives a measure of Q', the specific removal rate (Table 3). Grinding was conducted at two different conditions where the equivalent chip thickness [8] was kept constant. Initial tests were conducted at a wheel speed of $45 \mathrm{~m} / \mathrm{s}$, with a traverse-rate of $229 \mathrm{~mm} / \mathrm{min}$, corresponding to a Q' of 4.8 $\mathrm{mm} 3 / \mathrm{mm} / \mathrm{s}$. A second, more aggressive grinding test was considered at a traverse rate of 305 $\mathrm{mm} / \mathrm{min}$, corresponding to a $30 \%$ higher Q' of $6.5 \mathrm{~mm} / \mathrm{mm} / \mathrm{s}$. For these higher Q' tests, a wheel speed of $60 \mathrm{~m} / \mathrm{s}$ was used.

Water-soluble coolant (Master Chemical VHP-E320) at 5\% concentration was applied in the grinding zone using an entry and exit nozzle. Other grinding parameters are listed in Table 3. When grinding Inconel 718, there is a high probability of adherence of grinding debris to the wheel. Therefore, a cleaning jet, located away from the grinding zone, and operating at a pressure of 34 bar was directed towards the wheel.

Table 1: Wheel specification and truing conditions

\begin{tabular}{|l|l|}
\hline Wheel dimension $(1 \mathrm{~A} 1)$ & $178(\mathrm{OD}) \times 6.35($ wide $) \mathrm{mm} ; 3 \mathrm{~mm}$ CBN layer \\
\hline Wheel specification & $100 / 120(\mathrm{~B} 151), 120$ concentration \\
\hline Truing device & Powered rotary \\
\hline Truing wheel $(1 \mathrm{~A} 1)$ & $152(\mathrm{OD}) \times 2.54($ wide $) \mathrm{mm}$ \\
\hline Truing wheel specification & Diamond $(\mathrm{MBS} @ 95040 / 50) ;$ Metal bond; 50 conc. \\
\hline Speed ratio & $0.4($ Uni-directional $)$ \\
\hline Radial infeed per pass & $1.3 \mu \mathrm{m}$ \\
\hline Truing lead per revolution $\left(\mathrm{s}_{\mathrm{d}}\right)$ & $254 \mu \mathrm{m}(0.010$ in $)$ \\
\hline
\end{tabular}

Table 2: Inconel 718 nominal composition

\begin{tabular}{|l|l|l|l|l|l|l|l|l|l|l|l|}
\hline & $\mathrm{Ni}$ & $\mathrm{Cr}$ & $\mathrm{Mo}$ & $\begin{array}{l}\mathrm{Nb}+ \\
\mathrm{Ta}\end{array}$ & $\mathrm{Ti}$ & $\mathrm{Al}$ & $\mathrm{C}$ & $\mathrm{Mn}$ & $\mathrm{Si}$ & $\mathrm{B}$ & $\mathrm{Fe}$ \\
\hline $\mathrm{Wt} \%$ & $\begin{array}{l}50- \\
55\end{array}$ & $17-$ & $\begin{array}{l}2.8- \\
21\end{array}$ & $\begin{array}{l}4.75- \\
5.5\end{array}$ & $\begin{array}{l}0.65- \\
1.15\end{array}$ & $\begin{array}{l}0.2- \\
0.8\end{array}$ & 0.08 & 0.35 & 0.35 & $\begin{array}{l}0.00 \\
6\end{array}$ & $\mathrm{Bal}$ \\
\hline
\end{tabular}

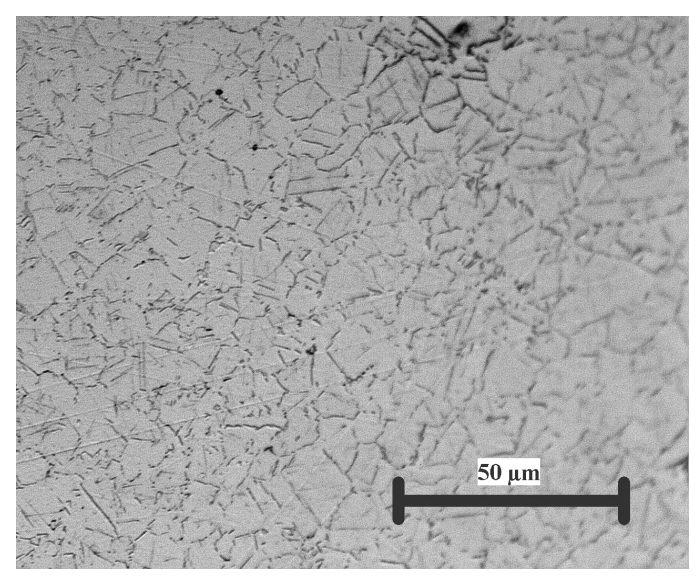

Figure 3: Microstructure of as-received Inconel 718 workpiece; etched with Tucker's Etch for 25 sec 
Table 3: Grinding parameters

\begin{tabular}{|l|l|}
\hline Machine & Blohm Precimat CNC surface grinder, $15 \mathrm{hp}$ \\
\hline Grind mode & Creep-feed (up-cut) \\
\hline Wheel & Vitrified bond, med. hardness, induced + open porosity \\
\hline Workpiece & Inconel 718 $(35 \mathrm{HRC})$ \\
\hline Wheel speed, $\mathrm{V}_{\mathrm{s}}$ & $45,60 \mathrm{~m} / \mathrm{s}$ \\
\hline Depth of cut, $\mathrm{a}_{\mathrm{e}}$ & $1.27 \mathrm{~mm}$ \\
\hline Table speed, $\mathrm{v}_{\mathrm{w}}$ & $229,309 \mathrm{~mm} / \mathrm{min}$ \\
\hline Width of cut, $\mathrm{b}_{\mathrm{d}}$ & $3.3 \mathrm{~mm}$ \\
\hline Specific MRR, $\mathrm{Q}_{\mathrm{w}}^{\prime}$ & $4.8,6.5 \mathrm{~mm} 3 / \mathrm{mm} / \mathrm{s}$ \\
\hline High-pressure cleaning jet & $11 \mathrm{l} / \mathrm{min}$ at 34 bar \\
\hline Coolant & Master Chemical VHPE-320 at $5 \%$ conc. \\
\hline Coolant flow & $151 \mathrm{l} / \mathrm{min}$ at 8.3 bar (Entry \& exit nozzles) \\
\hline
\end{tabular}

Test procedure

To facilitate wheel wear measurement, only a portion of the wheel width was used for the test. Though the wheel was $6.35 \mathrm{~mm}$ wide, the width of cut was maintained at $3.3 \mathrm{~mm}$. This enabled the use of the un-used portion of the wheel as a reference surface from which to monitor wheel wear. After a pre-determined volume of the Inconel 718 workpiece was ground, the entire width of the wheel was used to take a shallow cut in a soft steel workpiece. The resultant wheel trace on the soft steel block was recorded using a stylus-based profilometer. Such a trace provided a measure of the wheel wear relative to the un-used (reference) wheel surface and, therefore, the wheel life. Tests were continued until the attainment of a steady-state condition as measured by radial wheel wear and power. Alternatively, when the surface finish $\left(\mathrm{R}_{\mathrm{Z}}\right)$ exceeded $4.6 \mu \mathrm{m}$, it was an indication of a need for wheel re-conditioning and of test termination.

Performance metrics

Grinding performance was measured as a function of grinding wheel wear, specific energy, and the workpiece surface finish. Wheel life is commonly reported in non-dimensional units called grinding ratio (G-ratio) expressed as a ratio of volume of material ground to the volume of wheel worn. For all other things being equal, a higher G-ratio is indicative of better wheel life.

Specific energy is a measure of the efficiency of the grinding process, measured as the energy consumed per unit volume of material ground. A lower value indicates that a smaller fraction of the grinding energy is dissipated in non-productive deformation or frictional interaction. To compute specific energy, the grinding spindle power was digitized and acquired using a Halleffect sensor on the spindle motor. A Hommel surface profilometer (T4000) was used to measure the workpiece surface finish, $\mathrm{R}_{\mathrm{Z}}$, in addition to recording the wheel wear traces. Thermal damage was qualitatively assessed by inspecting the ground workpiece for visible discoloration.

Wheel wear

\section{Results and Discussion}

Figure 4 shows the G-ratio of the three $\mathrm{CBN}$ crystals. At the lower $\mathrm{Q}=4.8 \mathrm{~mm}^{3} / \mathrm{mm} / \mathrm{s}, \mathrm{CBN} B$ and $\mathrm{C}$ outperformed $\mathrm{CBN}$ A. CBN B had a wheel life that is $4 \times$ that with CBN A while CBN C is $1.7 \times$ better than $\mathrm{CBN}$ B. Testing $\mathrm{CBN} A$ at the accelerated $\mathrm{Q}^{\prime}=6.5$ was deemed to be a moot point. At $\mathrm{Q}^{\prime}=6.5, \mathrm{CBN} B$ experienced a drop of $35 \%$ relative to its performance at $\mathrm{Q}=4.8$. Similarly, CBN C also shows a drop of about $44 \%$. It should be noted, however, that G-ratio with $\mathrm{CBN} C$ at $\mathrm{Q}^{\prime}=6.5$ is still $44 \%$ better than $\mathrm{CBN}$ B. 


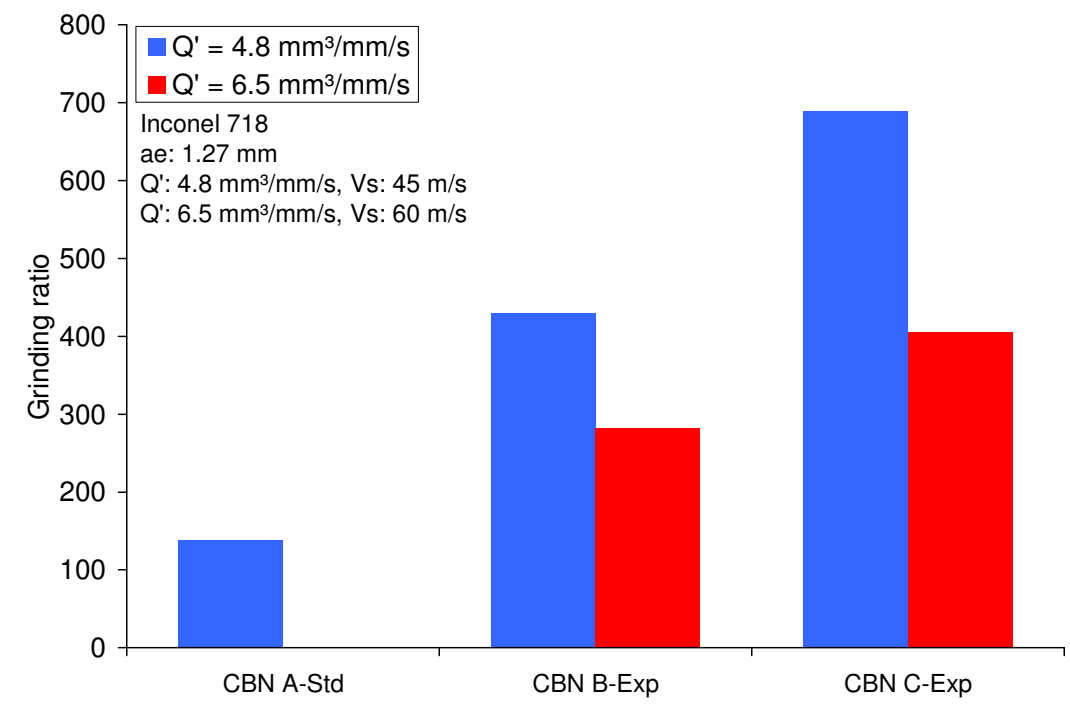

Figure 4: Comparison of grinding ratio at two different removal rates $\left(\mathrm{Q}^{\prime}\right)$

Figure 5 shows the progression of radial wheel wear as a function of the volume ground at the two different removal rates. At Q'=4.8 CBN A displays consistently high wheel wear throughout the test. $\mathrm{CBN} C$ shows the least and slowest wear of all the wheels. At test termination (steady state), $\mathrm{CBN} C$ had $17 \mu \mathrm{m}$ of wear compared to $26 \mu \mathrm{m}$ for CBN B and $67 \mu \mathrm{m}$ for CBN A. The higher wear at $Q^{\prime}=6.5$ (hollow symbols on chart) is apparent. Even with the best performing crystal - CBN C - the higher Q' limits the total volume ground to about 70\% of that at Q'=4.8.

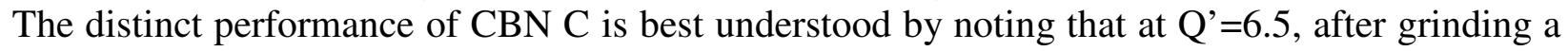
volume of $13 \mathrm{~cm}^{3}$, CBN C shows $30 \%$ lower wheel wear at $18 \mu \mathrm{m}$ compared to $26 \mu \mathrm{m}$ with CBN B.

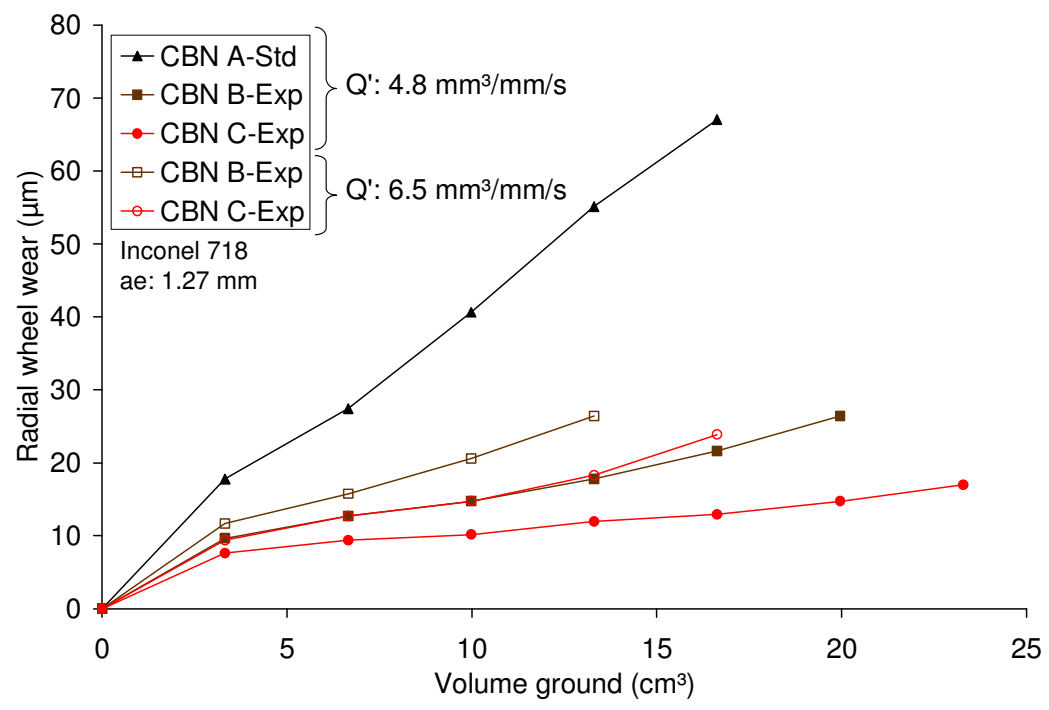

Figure 5: Radial wheel wear as a function of volume ground. CBN A not tested at Q'=6.5

Specific grinding energy

The maximum specific energy recorded in each of the two test conditions is shown in Figure 6. The visible burn threshold, estimated to be about $205 \mathrm{~J} / \mathrm{mm}^{3}$ was reached by CBN A. Workpieces ground with $\mathrm{CBN} \mathrm{B}$ and $\mathrm{C}$ showed no signs of visible workpiece burn. In fact, $\mathrm{CBN}$ $\mathrm{C}$, the best performing wheel (Figure 4) shows a 10\% lower specific energy than does CBN B at 
$Q^{\prime}=4.8$. When grinding at $Q^{\prime}=6.5$, it is to be noted that the specific energy declined relative to that at $Q^{\prime}=4.8$. This phenomenon is likely related to the higher radial wear and the consequent emergence of new cutting edges at $Q^{\prime}=6.5$ compared to that at $Q^{\prime}=4.8$.

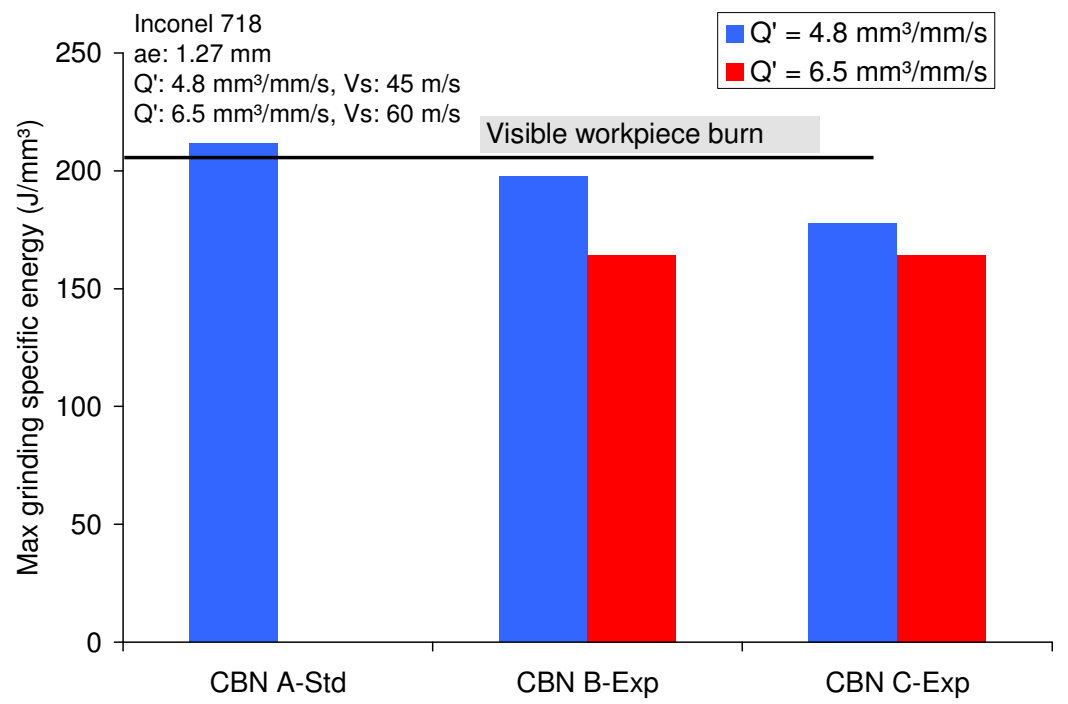

Figure 6: Max specific energy. CBN-A caused visible grinding burn at $Q^{\prime}=4.8$.

The evolution of grinding specific energy as a function of volume ground is shown in Figure 7. It is clear that beyond the initial break-in (subsequent to wheel conditioning), CBN A consistently has higher energy requirements. The controlled breakdown of CBN C (Figure 5) ensures that it settles into a steady lower-power mode for the duration of the test.

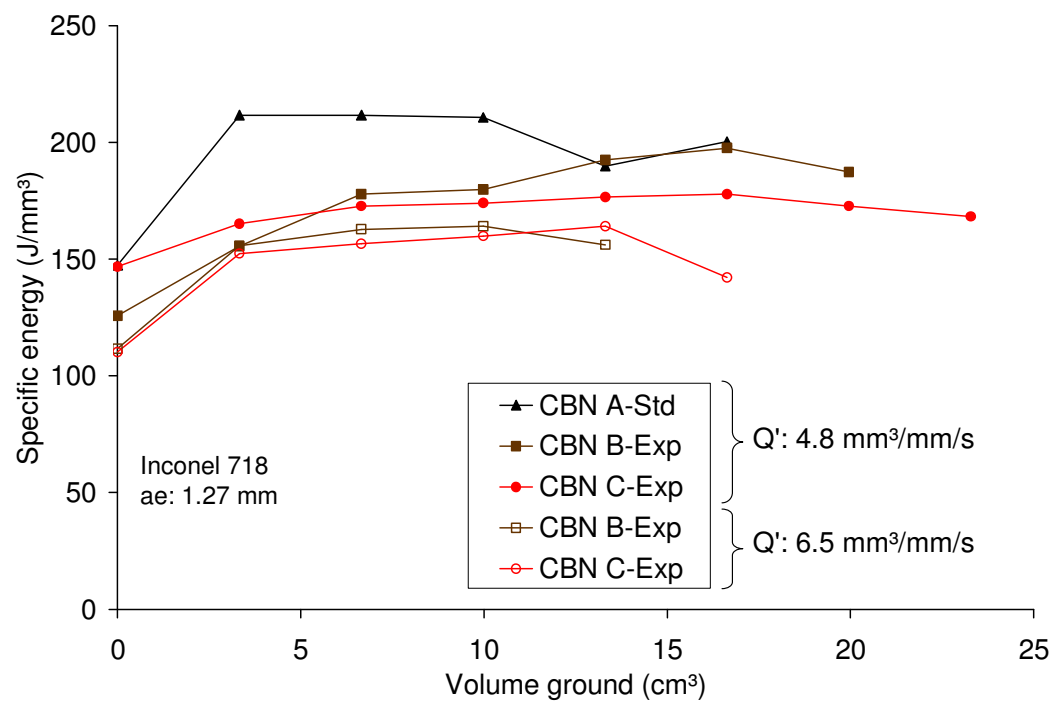

Figure 7: Variation of specific energy with volume ground. CBN A not tested at Q'=6.5

\section{$\underline{\text { Surface finish }}$}

The evolution of surface finish, $\mathrm{R}_{\mathrm{Z}}$, is shown in Figure 7. At $\mathrm{Q}^{\prime}=4.8$, the rapid wear of CBN A manifests itself as continually rougher $R_{Z}$ as a function of volume ground. The $\mathrm{Rz}$ values range from $2.5 \mu \mathrm{m}$ to $4.8 \mu \mathrm{m}$. CBN C shows a smaller $\mathrm{R}_{\mathrm{Z}}$ range of $2 \mu \mathrm{m}$ to $2.9 \mu \mathrm{m}$. At the elevated $Q^{\prime}=6.5$, the higher wheel wear (Figure 4) translates to higher $R_{Z}$ for the same volume ground. In fact, testing with CBN B was terminated due to exceeding the previously imposed $\mathrm{R}_{\mathrm{Z}}$ threshold. 
It is likely that $\mathrm{CBN} \mathrm{C}$ would not have been able to grind much more volume while maintaining $\mathrm{R}_{\mathrm{Z}}<4.6 \mu \mathrm{m}$.

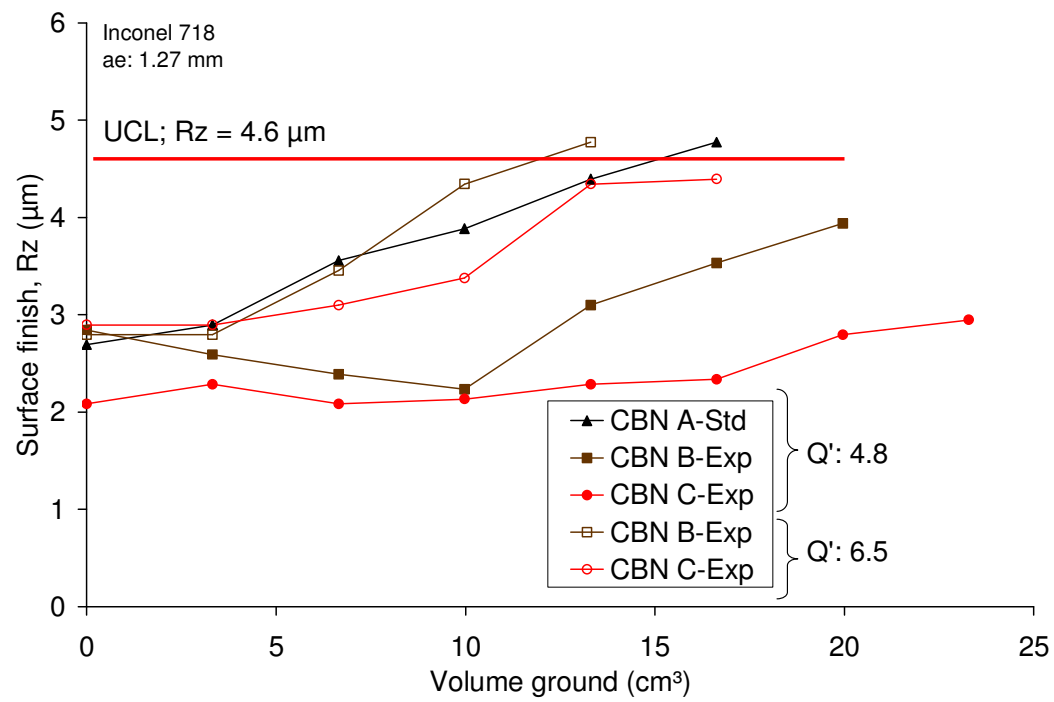

Figure 8: Evolution of surface finish $\left(\mathrm{R}_{\mathrm{Z}}\right) . \mathrm{CBN}$ A not tested at $\mathrm{Q}^{\prime}=6.5$

$\underline{\text { Discussion }}$

Thermal toughness appears to be a determinant of performance in Inconel 718 grinding. Low TTI crystals like CBN A can be outperformed by those with high TTI like CBN B and C. The poor thermal properties of Inconel 718 mean that the energy partition coefficient for CBN is necessarily high. The inability of $\mathrm{CBN} A$ to adequately dissipate this energy results in an accelerated crystal wear.

However, TTI does not completely explain grinding performance. In spite of possessing essentially similar TTI (and TI), CBN C significantly outperforms CBN B at both chosen Q' levels. Furthermore, the shape and color of both $\mathrm{CBN} B$ and $\mathrm{C}$ crystals are similar, eliminating these attributes as the factors that could explain the grinding differences.

The superior performance of CBN C is most likely due to the controlled breakdown of its crystals and cutting edges. This ensures that energy requirements of $\mathrm{CBN} \mathrm{C}$ with given grinding conditions remain steady. With adequate coolant flow and no superalloy swarf adhesion to the wheel, controlled crystal wear, stable energy and associated energy partitioning assist with maintaining part geometry and microstructural properties.

\section{Conclusions}

Three CBN crystal types - A, B, C - were tested in creep feed grinding of Inconel 718. CBN A, which shows the least thermally stability while possessing a blocky shape, shows high wheel wear and was significantly outperformed by CBN B and CBN C.

Experimental versions of CBN - labeled CBN B and C - which show much higher thermal stability, demonstrate correspondingly higher G-ratio at $\mathrm{Q}^{\prime}=4.8$.

Traditional superalloy grinding processes are limited by the ability of the CBN crystal and confined to low removal rates in the range of $Q^{\prime}=4.8$. Both $\mathrm{CBN} B$ and $\mathrm{C}$ expand the accessible space of material removal rate (Q') values and enable higher throughput without causing any 
thermal damage in the workpiece. Not surprisingly, at the higher Q' $=6.5$, both $\mathrm{CBN} B$ and $\mathrm{C}$ wear more quickly and impart a rougher surface finish to the workpiece. In practical terms, higher productivity is thus achievable with the same installed machine capacity. However, the cost justification for employing a higher Q' has to be carefully analyzed based on the requirements of the application

As lower thermal conductivity superalloy materials are being developed, the wide range of grinding regimes enabled by $\mathrm{CBN} \mathrm{B}$ and $\mathrm{CBN} \mathrm{C}$ could aid in establishing efficient finish manufacturing processes.

\section{Acknowledgments}

The authors thank Diamond Innovations for providing CBN crystals B and C; Mr. J.H. Fiecoat for conducting the grinding tests; and the Grinding Product Management for test support.

\section{References}

1. R.C. Reed, T. Tao, and N. Warnken, "Alloys-By-Design: Application to nickel-based single crystal superalloys," Acta Materialia, 59 (19) (2009), 5898-5913.

2. J. Perepzeko, “The Hotter the Engine, the Better," Science, 326 (2009), 1068-1069.

3. Inconel 718 Technical Spec Sheet, http://www.espimetals.com/tech/inconel718.pdf.

4. D.J. Stephenson, E. Laine, I. Johnstone, A. Baldwin, and J. Corbett, "Burn Threshold Studies for Superabrasive Grinding Using Electroplated CBN Wheels," (Paper presented at 4th International Machining \& Grinding Conference, 7-10 May 2001, Troy, Michigan) SME Technical Paper MR01219 (2001), 1-14.

5. J. Haines, J.M. Léger, and G. Bocquillon, "Synthesis and design of superhard materials," Annual Review of Materials Research, 31 (2001), 1-23.

6. K.V. Kumar, T. Ishikawa, and J. Koskey, 1991, "Superabrasive grinding of superalloys," (Paper presented at Superabrasives '91, 11-13 June 1991, Chicago, Illinois) SME Technical paper MR91$216,17,17-30$.

7. Diamond Innovations, Borazon CBN Product Selection Guide (2004), Worthington, USA.

8. J. Peters, R. Snoeys, and A. Decneut, "The significance of chip thickness in grinding," Annals of the CIRP, 23 (2) (1974), 227-237. 